\title{
Der Bürgermeister zieht ein MVZ hoch
}

\author{
Im ländlichen Schleswig-Holstein wächst das Interesse an kommunalen Betreiberkonzepten. Die Ärzte- \\ genossenschaft Nord hilft den Gemeinden - und stößt mancherorts auf ungeahnte Widerstände.
}

_ Das Interesse von Kommunen an Betreiberkonzepten für die ambulante ärztliche Versorgung steigt. Die Ärztegenossenschaft Nord begleitet derzeit neun Gemeinden in Schleswig-Holstein und Niedersachsen, die Konzepte für eigene Modelle erstellen lassen oder auch schon realisiert haben. „Die Bürgermeister sind deutlich stärker für dieses Thema sensibilisiert als noch vor drei, vier Jahren“, erklärt Genossenschaftschef Dr. Klaus Bittmann. Hauptgrund für ihn: das mangelnde Interesse junger Ärzte an Einzelpraxen auf dem Land.

Zwei Kommunen haben ihr Konzept nach Angaben von Genossenschafts-Geschäftsführer Thomas Rampoldt bereits umgesetzt. Das bundesweit bekannte Pioniermodell in Büsum vollzieht gerade den Generationswechsel. Die zuvor selbstständig niedergelassenen Ärzte brachten ihre Arztsitze in das kommunale Ärztezentrum ein. Nun gehen sie nach und nach in den Ruhestand, und jüngere Ärzte rücken nach. Für dieses Modell nach $₫ 105$ Abs. 5 SGB V hatte die KV Schleswig-Holstein umfangreiche Fördermittel zur Verfügung gestellt und eine Genehmigung erteilt.

Das Modell auf der Insel Pellworm dagegen ist ein kommunales Medizinisches Versorgungszentrum (MVZ) auf der Rechtsgrundlage des $₫ 95$ SGB V. Auch hier gelang der Generationswechsel durch Anstellung, nachdem der frühere Inselarzt für die Einzelpraxis keinen Nachfolger finden konnte.

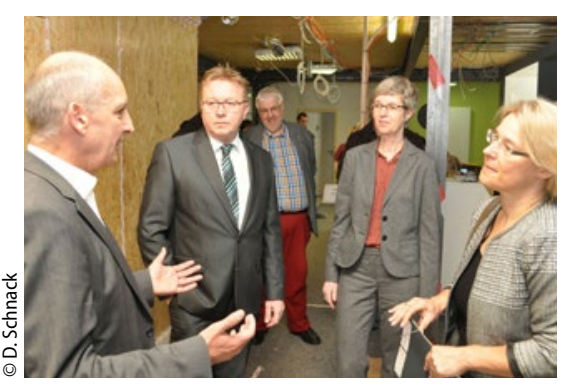

Thomas Rampoldt (I.) von der Ärztegenossenschaft Nord führt durch die kommunale Eigeneinrichtung in Büsum.

In Niedersachsen führt die Ärztegenossenschaft Nord derzeit im Auftrag der Kommunen Gespräche mit den Ärzten in Sittensen und Harsefeld. „Erstes Ziel ist für uns immer, Ärzte von einer selbstständigen Tätigkeit vor Ort zu überzeugen“, sagt Rampoldt dazu. Und auch für solch alternative Konzepte wie den kommunalen Zentren sei der Konsens mit den Ärzten vor Ort wichtig.

\section{Kommunale Kirchturmpolitik}

Glücklicherweise findet man fast immer zusammen. „Auch die Kollegen, die noch länger aktiv sind, brauchen ja die Entlastung“, berichtet Bittmann. „In aller Regel können sie die Patienten der in Ruhestand gehenden Kollegen nicht auch noch behandeln." Solche Gespräche führen die Genossenschaftler gegenwärtig noch an fünf weiteren Standorten in Schleswig-Holstein.

Neben dem Agreement der Ärzte ist aber auch ein Konsens unter den Bürger-

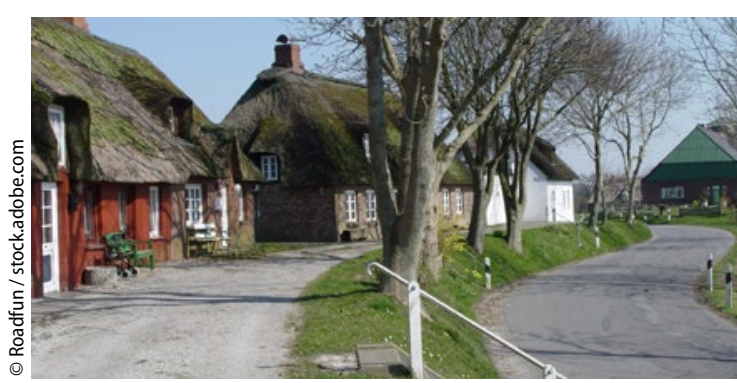

Landidyll: Auf der Insel Pellworm hat ein kommunales MVZ die Praxis des ehemaligen Inselarztes ersetzt.

meistern einer Region nötig, wenn diese gemeinsame Konzepte in Auftrag geben. Und an dieser Stelle hapert es bisweilen. Im schleswig-holsteinischen Amt Arensharde etwa konnten sich die Bürgermeister der beteiligten Gemeinden nicht auf die zwei von der Ärztegenossenschaft vorgeschlagenen Standorte für Ärztezentren einigen. Nun will eine der Gemeinden in Eigenregie ein Ärztezentrum etablieren. Ob die Praxen in den anderen Gemeinden Nachfolger finden, bleibt offen.

Von solcher Kirchturmpolitik, da ist Rampoldt überzeugt, werden sich die Bürgermeister verabschieden müssen, wenn sie dauerhaft Ärzte in der Region halten wollen. In jedem Fall haben die Genossenschaftler Konzeption und Umsetzung solcher Modelle zu einem neuen Geschäftszweig gemacht. Bittmann sieht darin sogar ein potenzielles Aushängeschild seiner Ärztegenossenschaft.

Dirk Schnack 